\title{
Verificação da eficiência de um dispositivo de desinfecção por radiação UV-C
}

\author{
Efficiency verification of a UV-C radiation disinfection device \\ Verificación de la eficacia de un dispositivo de desinfección por radiación UV-C
}

\author{
Alexsandro Silvestre da Rocha \\ ORCID: https://orcid.org/0000-0002-9469-6082 \\ Universidade Federal do Norte do Tocantins, Brasil \\ E-mail: alexsandro@uft.edu.br \\ Cláudia Adriana da Silva \\ ORCID: https://orcid.org/0000-0003-1666-3864 \\ Universidade Federal do Norte do Tocantins, Brasil \\ E-mail: claudia.a.dasilva@uft.edu.br \\ Regina Léllis de Sousa \\ ORCID: https://orcid.org/0000-0002-7145-5147 \\ Universidade Federal do Norte do Tocantins, Brasil \\ E-mail: rlsousa@uft.edu.br \\ Nilo Maurício Sotomayor Choque \\ ORCID: http://orcid.org/0000-0002-8952-1907 \\ Universidade Federal do Norte do Tocantins, Brasil \\ E-mail: nmsch@uft.edu.br \\ Denisia Brito Soares \\ ORCID: https://orcid.org/0000-0002-9223-5303 \\ Universidade Federal do Norte do Tocantins, Brasil \\ E-mail: denisiabrito@uft.edu.br \\ Eskálath Morganna Silva Ferreira \\ ORCID: https://orcid.org/0000-0002-2298-3656 \\ Universidade Federal do Tocantins, Brasil \\ E-mail:morganna@uft.edu.br \\ Mirelle Ribeiro Araújo \\ ORCID: https://orcid.org/0000-0001-6535-9928 \\ Universidade Federal do Tocantins, Brasil \\ E-mail: mirellera84@gmail.com \\ Juliana Fonseca Moreira da Silva \\ ORCID: https://orcid.org/0000-0002-9588-6718 \\ Universidade Federal do Tocantins, Brasil \\ E-mail: julianafmsilva@mail.edu.br \\ Raphael Sanzio Pimenta \\ ORCID: https://orcid.org/0000-0001-7207-4437 \\ Universidade Federal do Tocantins, Brasil \\ E-mail: pimentars@uft.edu.br
}

\begin{abstract}
Resumo
A Pandemia COVID-19, causada pelo vírus SARS-COV-2, evidenciou a necessidade de desenvolvimento de métodos seguros e economicamente viáveis para a realização de desinfecções em escala comercial e doméstica. Os coronavírus são mais suscetíveis à radiação UV-C do que fungos e bactérias e diversos estudos relacionados à eficiência da UVC contra o vírus causador da COVID-19 já foram realizados utilizando micro-organismos substitutos. Desta forma, este estudo buscou o desenvolvimento de um dispositivo acessível a usuários leigos para utilização em materiais que não podem ser submetidos a métodos convencionais de eliminação de micro-organismos (desinfecção química ou térmica). Esta pesquisa propôs a produção e validação de um dispositivo emissor de radiação UV-C portátil para a desinfeção de substratos suscetíveis a contaminação por bactérias, fungos e vírus patogênicos. O dispositivo foi desenvolvido a partir de materiais acessíveis a grande parte das empresas e população. Em seguida foi realizada a validação da eficiência do dispositivo através da exposição de culturas microbianas (bactéria Gram positiva, negativa e levedura) em diferentes intervalos de tempo. O dispositivo foi desenvolvido plenamente a partir de materiais de baixo custo e acessíveis. Todos os micro-organismos testados (Candida albicans, Staphylococcus aureus e Escherichia coli) foram eliminados do meio de cultura com menos de $20 \mathrm{~min}$. de exposição. O dispositivo desenvolvido neste estudo pode ser construído por boa parte das empresas e população. O dispositivo se mostrou eficaz para reduzir o risco de contágio de diferentes micro-organismos patogênicos, sugerindo sua efetividade contra SARS- COV-2 causador da pandemia COVID-19.
\end{abstract}

Palavras-chave: Esterilização; Desinfecção; Micro-organismo; SARS- COV-2; COVID-19; Radiação ultra violeta. 


\begin{abstract}
The COVID-19 pandemic, caused by the SARS-COV-2 virus, highlighted the need to develop safe and economically viable methods for carrying out disinfections on a commercial and domestic scale. Coronaviruses are more susceptible to UV-C radiation than fungi and bacteria and several studies related to the efficiency of UVC against the virus that causes COVID-19 have already been carried out using substitute microorganisms. Thus, this study sought to develop a device accessible to lay users for use in materials that cannot be subjected to conventional methods of eliminating microorganisms (chemical or thermal disinfection). This research proposed the production and validation of a portable UV-C emitting device for the disinfection of substrates susceptible to contamination by bacteria, fungi and pathogenic viruses. The device was developed from materials accessible to most companies and the population. Then, the device's efficiency was validated by exposing microbial cultures (Gram positive, negative bacteria and yeast) at different time intervals. The device was developed entirely from low-cost and accessible materials. All tested microorganisms (Candida albicans, Staphylococcus aureus and Escherichia coli) were removed from the culture medium in less than 20 min. exposure. The device developed in this study can be built by most companies and the population. The device proved to be effective in reducing the risk of contagion from different pathogenic microorganisms, suggesting its effectiveness against SARS-COV-2 that causes the COVID-19 pandemic.
\end{abstract}

Keywords: Sterilization; Disinfection; Microorganism; SARS- COV-2; COVID-19; Ultraviolet radiation.

\title{
Resumen
}

La pandemia COVID-19, causada por el virus SARS-COV-2, destacó la necesidad de desarrollar métodos seguros y económicamente viables para realizar desinfecciones an escala comercial y doméstica. Los coronavirus son más susceptibles a la radiación UV-C que los hongos y las bacterias y ya se han realizado varios estudios relacionados con la eficiencia de los UVC frente al virus causante del COVID-19 utilizando microorganismos sustitutos. Así, este estudio buscó desarrollar un dispositivo accesible a usuarios no profesionales para su uso en materiales que no pueden ser sometidos a métodos convencionales de eliminación de microorganismos (desinfección química o térmica). Esta investigación propuso la producción y validación de un dispositivo emisor de radiación UV-C portátil para la desinfección de sustratos susceptibles de contaminación por bacterias, hongos y virus patógenos. El dispositivo se desarrolló a partir de materiales accesibles para la mayoría de las empresas y la población. Luego, se validó la eficiencia del dispositivo exponiendo cultivos microbianos (bacterias Gram positivas, negativas y levaduras) a diferentes intervalos de tiempo. El dispositivo fue desarrollado completamente a partir de materiales accesibles y de bajo costo. Todos los microorganismos analizados (Candida albicans, Staphylococcus aureus y Escherichia coli) se eliminaron del medio de cultivo en menos de $20 \mathrm{~min}$. exposición. El dispositivo desarrollado en este estudio puede ser construido por la mayoría de las empresas y la población. El dispositivo demostró ser efectivo para reducir el riesgo de contagio de diferentes microrganismos patógenos, lo que sugiere su efectividad contra el SARS-COV-2 que causa la pandemia de COVID-19.

Palabras clave: Esterilización; Desinfección; Microorganismo; SARS-COV-2; COVID-19; Radiación ultravioleta.

\section{Introdução}

As doenças infecciosas possuem grande habilidade de disseminação, pois podem ser transmitidas por diferentes meios, inclusive, em alguns casos, vírus, fungos e bactérias patogênicos podem permanecer ativos em superfícies mesmo fora do hospedeiro. Neste sentido, a descontaminação de ambientes ou superfícies é uma das medidas que podem ser adotadas para reduzir as probabilidades de infecções. Em geral, existe uma variedade de situações nas quais é necessária a desinfecção de materiais, como é o caso de equipamentos de proteção individuais não descartáveis, equipamentos médicos, pisos, sistemas de climatização, transporte público, elevadores, ambientes hospitalares, dispositivos eletrônicos, etc. (Van Doremalen, et al., 2020; Kampf, et al., 2020).

A Pandemia COVID-19, causada pelo vírus SARS-COV-2, evidenciou a necessidade de desenvolvimento de métodos seguros e economicamente viáveis para a realização de desinfecções em escala comercial e doméstica. A utilização de radiação UV-C para a descontaminação de substratos é reconhecida na literatura científica a décadas, sendo que os comprimentos de onda ideais para desinfecção estão próximos a $270 \mathrm{~nm}$ (Buonanno, et al., 2020).

O SARS-CoV-2 causador da Covid-19 é o terceiro coronavírus humano altamente patogênico que surgiu nas últimas duas décadas (Zhou, et al., 2020). Consiste em um vírus esférico, de RNA, envolto por um envelope que é constituído por camada dupla de lipídeos e proteínas estruturais (Dhama, et al., 2020), foi identificado em dezembro de 2019 como agente causal de uma série de casos de pneumonia na cidade chinesa de Wuhan (Morais, et al., 202; Silva, et al., 2021). 
Todavia, os coronavírus, devido suas características estruturais, são mais suscetíveis à radiação UV-C do que fungos e bactérias, e diversos estudos relacionados à eficiência da UV-C contra a COVID-19 já foram realizados utilizando microorganismos substitutos (Choi, et al., 2021; Cadnum, et al., 2020; Torres, et al., 2020). Este estudo buscou o desenvolvimento de um dispositivo acessível a usuários leigos para utilização em substratos que não podem ser submetidos a métodos convencionais de eliminação de micro-organismos (desinfecção química ou térmica) tais como dispositivos eletrônicos e ambientes de difícil acesso ou que necessitem de desinfecção sem contato direto.

\section{Metodologia}

\subsection{Desenvolvimento do dispositivo de desinfecção}

A equipe científica deste estudo desenvolveu o dispositivo de desinfecção a base de lâmpadas UV-C com a utilização de materiais simples, de baixo custo e acessíveis a grande parte da população e empresas. Para tanto foram utilizados os seguintes componentes (Tabela 1).

Tabela 1: Componentes utilizados no desenvolvimento do dispositivo.

\begin{tabular}{|c|c|}
\hline $\mathbf{N}^{\mathbf{0}}$ & Componentes \\
\hline 1 & $60 \mathrm{~cm}$ de cano PVC de $75 \mathrm{~mm}$. \\
\hline 2 & 2 Caps PVC de $75 \mathrm{~mm}$. \\
\hline 3 & 3 Parafusos $1 / 2$ zincados com fenda -1 ". \\
\hline 4 & 9 Arruelas zincadas para parafuso $1 / 2$. \\
\hline 5 & 3 Porcas zincadas para parafuso $1 / 2$. \\
\hline 6 & 1 Abraçadeira tipo $U-1 / 2$. \\
\hline 7 & $2 \mathrm{~m}$ de fio duplo PP $2 \times 2-5 \mathrm{~mm}-$ PTO. \\
\hline 8 & 1 Tomada macho universal, dois pólos, 10A - 250V. \\
\hline 9 & 1 Interruptor simples, 6A e 250V (adaptado ao dispositivo). \\
\hline 10 & $\begin{array}{l}\text { Lâmpada UV-C } 254 \mathrm{~nm} \text { de comprimento onda, } 25 \mathrm{~W} \text { T8 com } 45 \\
\text { cm. }\end{array}$ \\
\hline 11 & Reator $1 \times 32 \mathrm{~W}$ - Bivolt. \\
\hline 12 & Soquete tipo tomadinha $\mathrm{T} 8 \mathrm{com}$ rabicho. \\
\hline 13 & Presilha plástica T8 para lâmpada. \\
\hline
\end{tabular}

Fonte: Autores (2021).

A partir dos componentes citados anteriormente (Tabela 1) o equipamento foi montado conforme demonstrado na figura 1 (a e b), onde são apresentados o dispositivo finalizado e a vista explodida com os componentes. 
Figura 1. (A) Dispositivo UV-C. (B) Ilustração de forma explodida do dispositivo.

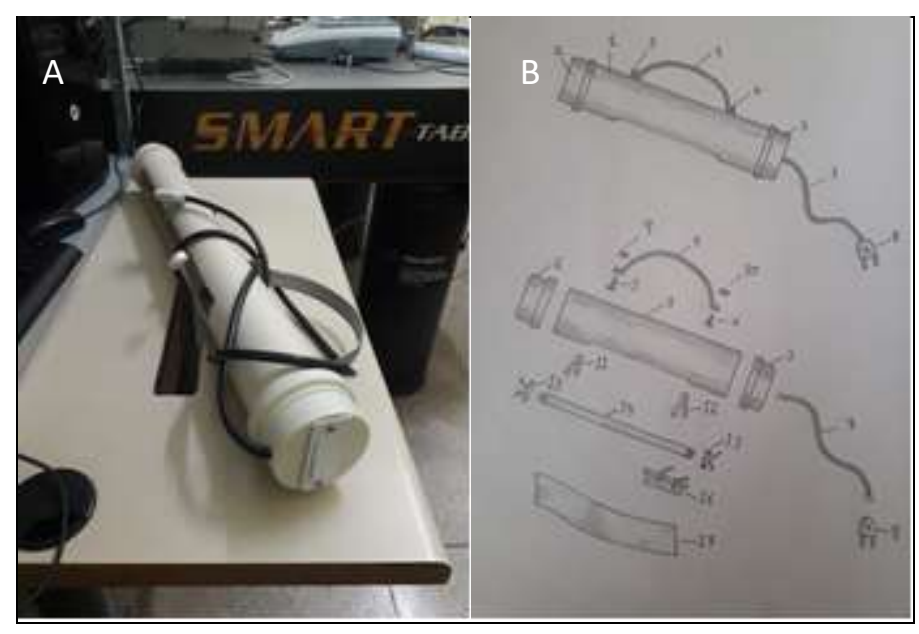

Fonte: Autores (2021).

O dispositivo foi desenvolvido artesanalmente com a ajuda de ferramentas elétricas e manuais, tais como: micro retífica, furadeira, serra, chave de boca e fenda, entre outras. O germicida UV-C com aproximadamente $60 \mathrm{~cm}$ de comprimento e $0,7 \mathrm{Kg}$ de peso constitui-se basicamente de um invólucro de Policloreto de Vinila (PVC) e uma lâmpada UV-C ( $\lambda=254 \mathrm{~nm}$ ). O dispositivo possui uma abertura inferior para emissão e direcionamento da radiação UV-C e uma alça superior para manuseio do usuário, ademais, o sistema elétrico (reator) fica embutido em seu interior.

\subsection{Simulações computacionais da Incidência de Radiação}

A quantificação da radiação à qual os patógenos são expostos constitui um dos requisitos essenciais no desenvolvimento de sistemas de desinfecção de superfícies empregando radiação ultravioleta (UVGI - sigla inglesa para Ultraviolet Germicidal Irradiation). Nos sistemas que empregam lâmpadas que emitem radiação UV, é importante que se conheça a intensidade de radiação por unidade de área na superfície do emissor. Todavia, é fundamental que se obtenha estimativa da intensidade irradiada a uma distância da lâmpada, $\mathrm{I}_{\mathrm{d}}$, e que atinge uma dada superfície o que possibilita o cálculo da quantidade de radiação que estará incidindo sobre o patógeno que se deseja eliminar. Há vasta literatura especializada em modelagem de transferência radiativa de calor e muitos desses estudos referem-se a modelos matemáticos para dimensionamento de sistemas UVGI (Kowalski, 2001; dos Santos et al., 2008; Kowalski, 2009; Modest, 2013).

Com o objetivo de se obter a quantidade de energia produzida pela lâmpada UV que é recebida em alguma área de superfície que se deseja irradiar, deve-se estimar o valor da grandeza física denominada "fator de forma" ou, equivalentemente, “fator de visão da radiação" (radiation view factor) (dos Santos et al., 2008; KowalskI, 2009; Modest, 2013).

O nome "fator de forma" faz menção ao fato de que são consideradas as características geométricas para estimar a intensidade de radiação que será interceptada por uma superfície. A intensidade irradiada a uma distância conhecida da lâmpada, $\mathrm{I}_{\mathrm{d}}$, pode ser obtida por meio da equação 1 (Kowalski, 2001; dos Santos, et al., 2008; Kowalski, 2009).

$$
I_{d}=\frac{P_{\text {lamp }-U V}}{2 \pi r l} F_{d A_{j}-A_{\text {catindro }}}^{\text {total }}=I_{0} F_{d A_{j}-A_{\text {celindro }}}^{\text {total }}
$$

sendo que $P_{\text {lomp-UV representa a potência emitida na superfície da lâmpada }}$ UV e $F_{d A_{j}-A_{\text {cilindro }}}$ representa o fator de forma. 
Segundo Modest (2013), o fator de forma infinitesimal, $\mathrm{dF}_{\mathrm{dAi}}$ - $\mathrm{dAj}$, é definido como sendo o quociente entre a energia deixando uma área infinitesimal $\mathrm{dA}_{\mathrm{i}}$ e que será interceptada diretamente por uma área infinitesimal $\mathrm{dA}_{\mathrm{j}}$ e energia total deixando $\mathrm{dA}_{\mathrm{i}}$. Há muitas estratégias para se estimar o fator de forma, $\mathrm{F}_{\mathrm{Ai}}$ - Aj, e pode-se, inclusive, realizar cálculos dessa grandeza envolvendo uma área infinitesimal $\mathrm{dA}_{\mathrm{i}}$ e uma área finita $\mathrm{A}_{\mathrm{j}}$. Muitas tabelas contendo os cálculos dos fatores de formas para geometria simples estão disponíveis porque os procedimentos de avaliação das integrais são factíveis.

Considerando o sistema UVGI em tela, pode-se realizar a estimativa de $I_{d}$ empregando um cilindro cujo comprimento, $l$, e o raio, $r$, correspondem às dimensões da lâmpada UV e a superfície $\mathrm{dA}_{\mathrm{j}}$ seria um elemento infinitesimal perpendicular ao eixo do cilindro e posicionado em sua extremidade. Neste caso, $F_{A i-A j}=F_{d A j}$ - Acilindro, tem a forma dada na equação 2 com os parâmetros definidos nas equações 3 e 4 .

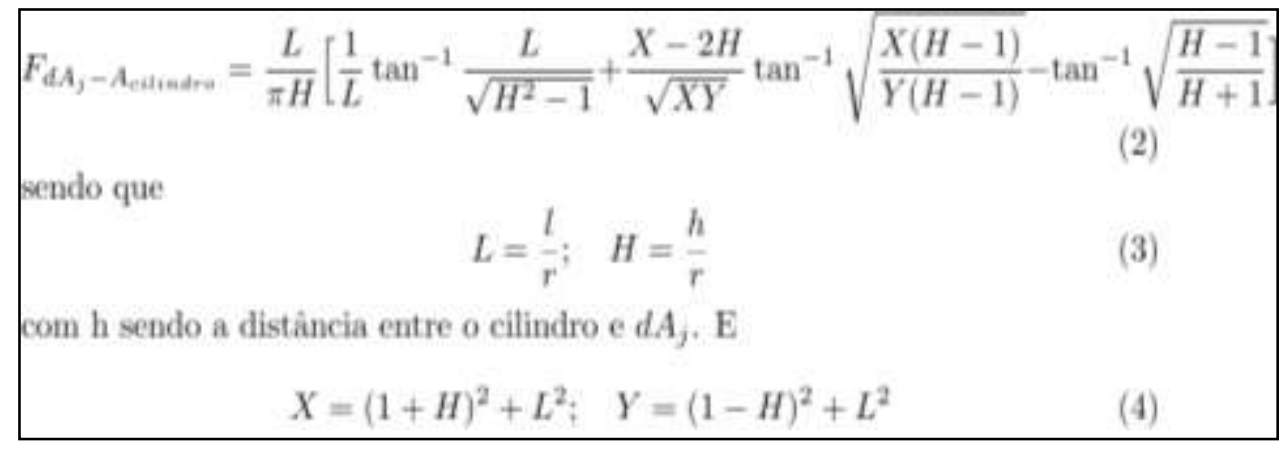

Considerando que $\mathrm{F}_{\mathrm{dAj}}$ - Acilindro está definido para um elemento de infinitesimal de área posicionado na parte final do cilindro, para se obter $I_{d}$ interceptado por um elemento de área posicionado no ponto médio da fonte emissora, basta dividir o comprimento da lâmpada em 2 seguimentos cuja soma se igualam ao tamanho total $l$, tal que $1=1_{1}+l_{2} \mathrm{e}$, em consequência, temos $l_{2}=1-1_{1}$. Mas, considerando que $l_{1}$ seja igual a $l_{2}$, o fator de forma total, $F^{\text {total }}$ dAj-Acilindro, será obtido somando os resultados de $\mathrm{F}_{\mathrm{dAj}}$ - Acilindro, para cada metade do comprimento total e teremos $\mathrm{F}^{\mathrm{total}}$ dAj-Acilindro $=2 * \mathrm{~F}_{\mathrm{dAj}}$ - Acilindro.

$\mathrm{O}$ cálculo dos valores de $\mathrm{I}_{\mathrm{d}}$ pode ser operacionalizado por meio de códigos computacionais ou mesmo utilizando planilhas eletrônicas (Modest, 2013). Vários catálogos contendo um conjunto diverso de fatores de forma para geometrias simples estão disponíveis para consulta on-line (Modest, 2013; Howell, 2021; Three-dimensional, 2021).

No nosso caso, utilizou-se um código computacional redigido em Fortran e para o qual os dados de entrada eram: potência, raio e comprimento da lâmpada e também o valor distância do ponto a ser irradiado em relação ao ponto médio da lâmpada. O resultado pode ser visualizado nas Figuras 2, 3 e 4. Utilizou-se, na Figura 2, uma função do tipo $\mathrm{a}^{*} \mathrm{x} *^{*}-2+\mathrm{b}^{*} \mathrm{x} * *_{-}$ $1+\mathrm{c}$ para o ajuste dos dados. Na Figura 3, repete-se o gráfico, mas com o ajuste utilizando função do tipo $\mathrm{a}^{*} \mathrm{x} *^{*}-3+\mathrm{b}^{*} \mathrm{x}^{* *}-2$ $+c^{*} \mathrm{x}-1+\mathrm{d}$. Os dados sem qualquer ajuste são aqueles da Figura 4. 
Research, Society and Development, v. 10, n. 6, e31310615817, 2021

(CC BY 4.0) | ISSN 2525-3409 | DOI: http://dx.doi.org/10.33448/rsd-v10i6.15817

Figura 2. Gráfico da radiação em função da distância mediante calculo com a função a*x**-2 $+\mathrm{b}^{*} \mathrm{x}^{*} *_{-}-1+\mathrm{c}$ para o ajuste dos dados.

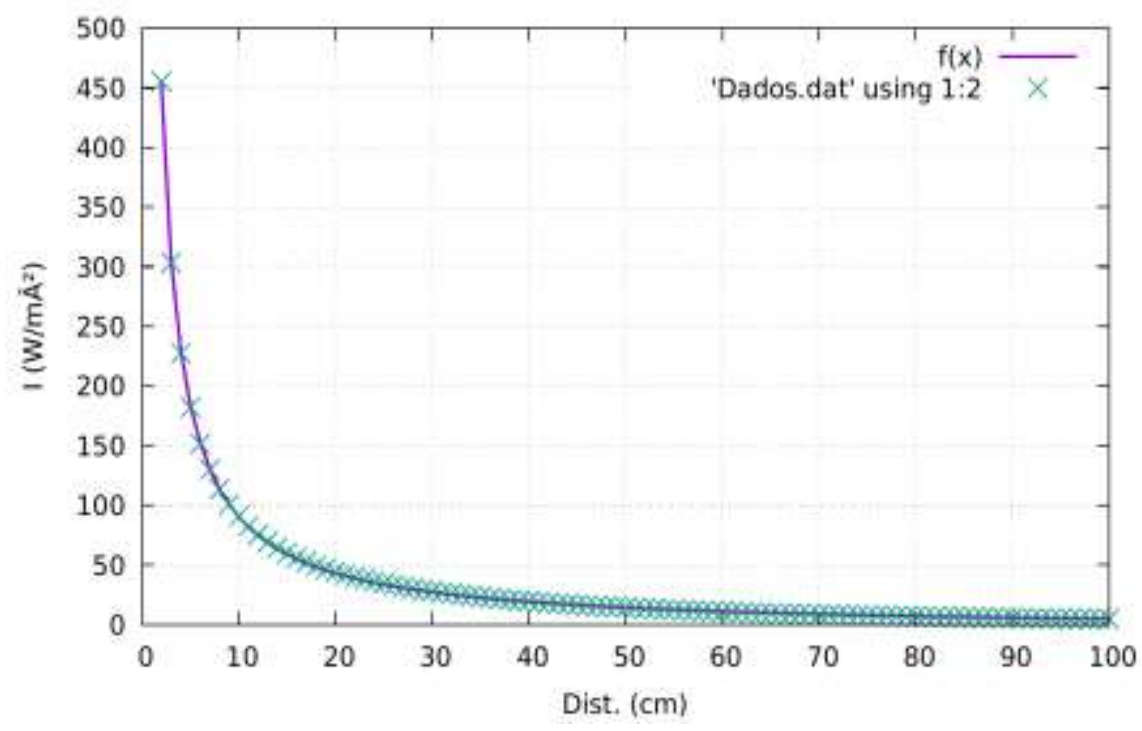

Fonte: Autores (2021).

Figura 3. Relação entre a radiação e distância mediante calculo com a função $a^{*} x^{*} *_{-} 3+b^{*} x^{*} *_{-} 2+c^{*} x-1+d$ para o ajuste dos dados.

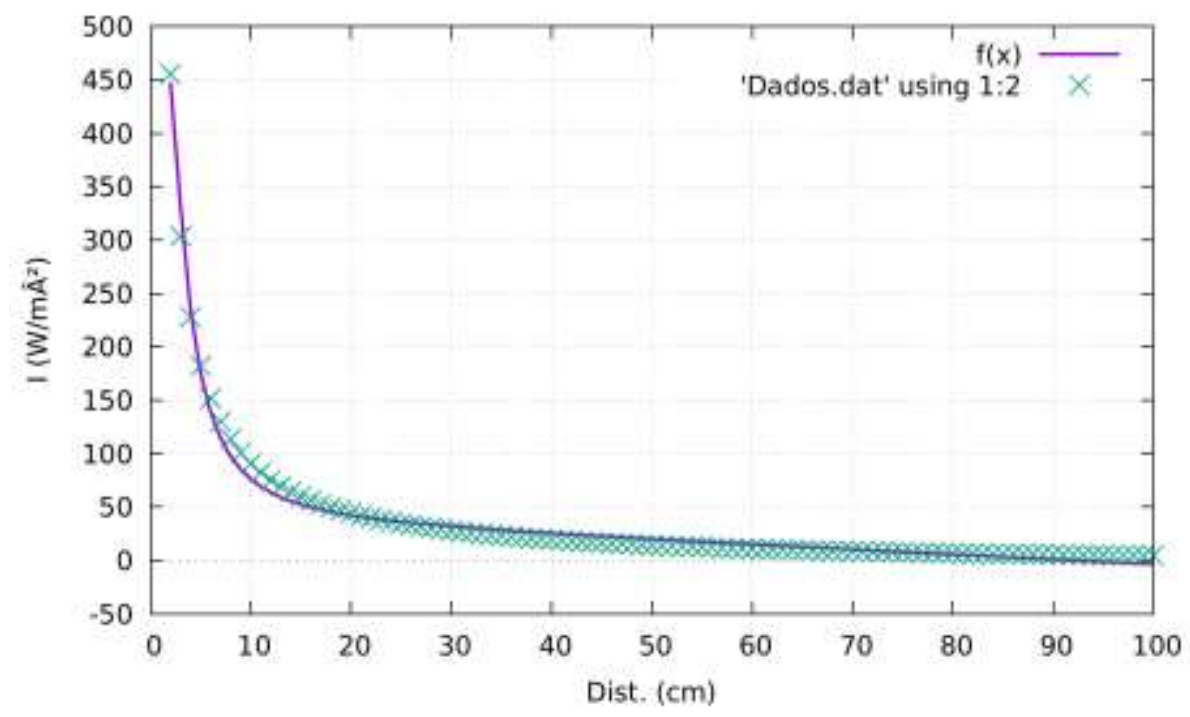

Fonte: Autores (2021). 
Figura 4. Relação entre a radiação e distância sem ajustes.

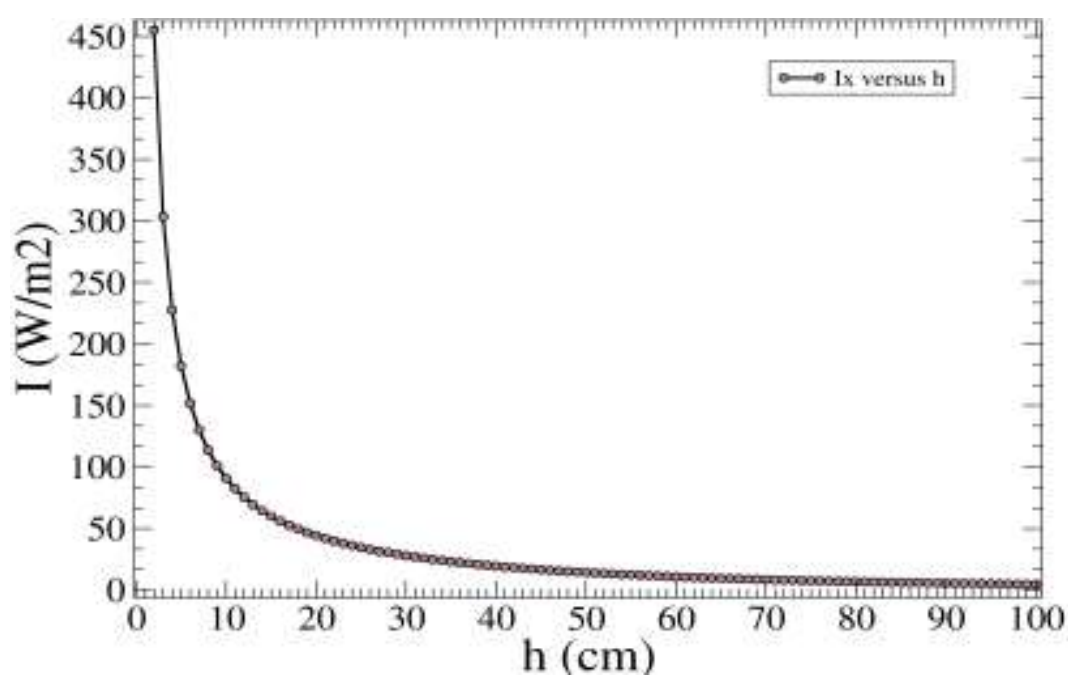

Fonte: Autores (2021).

Como um último comentário, ressalta-se que o cálculo da intensidade da radiação recebida por uma superfície situada a uma distância conhecida da lâmpada UV empregando a lei bem estabelecida de que a intensidade varia com inverso do quadrado da distância entre a superfície a ser irradiada e a lâmpada UV não é adequada para os sistemas UVGI em razão da proximidade entre a fonte e a superfície (Kowalski, 2001; Kowalski, 2009). O comportamento matemático nas proximidades da fonte seria diferente daquele obtido para pontos distantes.

\subsection{Verificação da eficiência do dispositivo}

Obtenção dos micro-organismos: A validação da eficiência do dispositivo foi realizada com a utilização de uma bactéria Gram-positiva (Staphylococcus aureus ATCC 6538) uma Gram-negativa (Escherichia coli ATCC 8739) e um fungo leveduriforme (Candida albicans ATCC 10231) adquiridos do Instituto Nacional de Controle de Qualidade Em Saúde (INCQS) da Fundação Oswaldo Cruz (FIOCRUZ) e estão depositados na coleção de culturas microbianas Carlos Augusto Rosa do Laboratório de microbiologia geral e aplicada da Universidade Federal do Tocantins - (UFT). Os micro-organismos foram retirados da coleção de culturas e reativados através do cultivo em ágar Sabouraud (levedura) e ágar nutriente (bactérias) e incubados a $25{ }^{\circ} \mathrm{C}$ por $48 \mathrm{~h}$. Em seguida foram transferidos para novas placas de Petri contendo os meios específicos e incubadas a $25^{\circ} \mathrm{C}$ por 24 h., para obtenção de biomassa.

\subsection{Sensibilidade à radiação UVC:}

Os inóculos iniciais dos micro-organismos foram obtidos através dos raspados das culturas cultivadas em placas de Petri com auxílio de uma alça de platina e transferidos para tubos de ensaio estéreis contendo $10 \mathrm{ml}$ de solução salina a $0,95 \%$. A concentração celular foi estimada com o uso de uma câmara de Neubauer e a concentração final ajustada para 105 células/ml. Em seguida as culturas foram inoculadas em placas de Petri contendo meio específico por um inoculador espiral (IUL ${ }^{\circledR}$ instruments, Espanha) em triplicata. Após a inoculação, todas as placas foram abertas e expostas à radiação UVC gerada pelo dispositivo sendo avaliados os seguintes tempos de exposição: 5, 10, 15, 20, 25 e min.

O dispositivo foi posicionado de forma a manter uma distância de 1 metro entre a fonte geradora da radiação e a superfície dos meios de cultura, e a incidência dos raios de forma perpendicular às culturas. Todos os experimentos foram realizados em triplicata. Após a exposição, as placas de Petri com as culturas irradiadas foram incubadas a $25^{\circ} \mathrm{C}$ por $24 \mathrm{~h}$. e a 
leitura do resultado foi obtida de forma eletrônica com auxílio de um contador automático de colônias (IUL® instruments, Espanha) e os resultados expressos em unidades formadoras de colônia (UFC) por ml.

\section{Resultados e Discussão}

O dispositivo foi montado e atendeu os seguintes critérios: 1 - baixo custo, 2 - fácil disponibilidade dos componentes, 3 - fácil montagem e 4 - eficiência em realizar a desinfeção.

O dispositivo desenvolvido neste estudo foi capaz de reduzir as populações microbianas de todos dos micro-organismos testados (C. albicans, E. coli e S. aureus) (Figs. 5 a 7). Segundo Szeto et al. (2020) ao analisarem um dispositivo semelhante, mas não portátil, observaram que este foi capaz de reduzir as populações de E. coli, S. aureus, e vírus da influenza em 6, 5 e 3,5 $\log _{10}$, após 10 min. de irradiação atingindo a desinfecção total de todos os patógenos após 20 min.

Importante salientar que o presente experimento para verificação da eficiência do dispositivo utilizou concentrações iniciais de micro-organismos da ordem de $10^{5}$ células por $\mathrm{ml}$ o que constitui uma população muito superior as normalmente observadas nas superfícies que serão submetidos à desinfecção. Outro fator relevante diz respeito ao substrato submetido a desinfecção (meios de cultura) no estudo, que favoreceram consideravelmente o crescimento dos micro-organismos ao contrário do que pode ser observado na maioria dos fômites que serão desinfectados.

Figura 5. Dinâmica de morte celular de Candida albicans submetida a diferentes tempos de exposição à radiação UV. A) sem exposição, B) após 5 min., C) após 10 min., D) após 15 min., E) após 20 min., F) após 30 min.

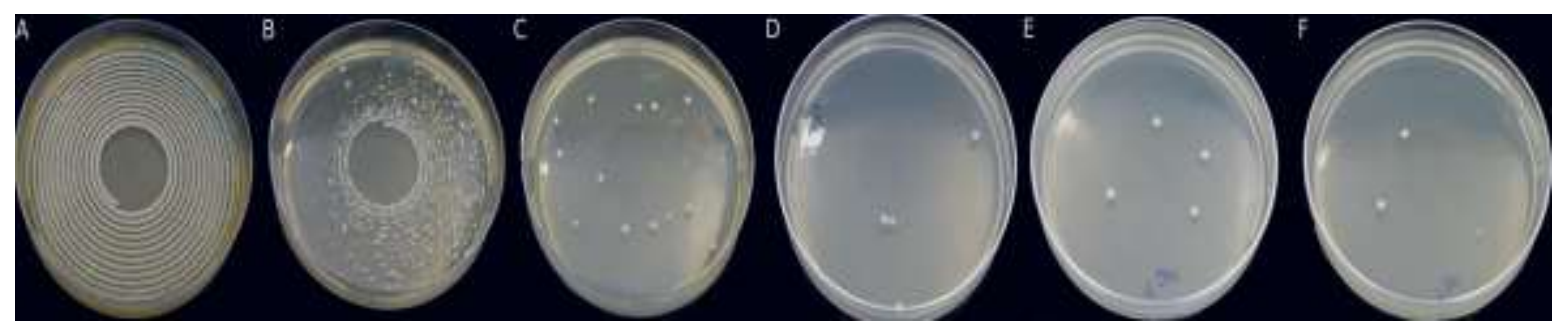

Fonte: Autores (2021).

Figura 6. Dinâmica de morte celular de Escherichia coli submetida a diferentes tempos de exposição à radiação UV. A) sem exposição, B) após 5 min., C) após 10 min., D) após 15 min., E) após 20 min., F) após 30 min.

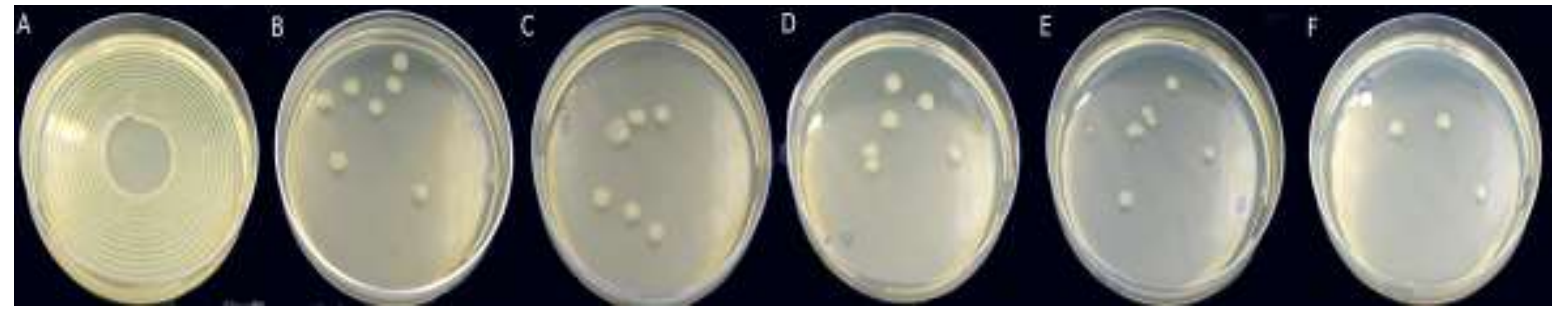

Fonte: Autores (2021). 
Figura 7. Dinâmica de morte celular de Staphylococcus aureus submetido a diferentes tempos de exposição à radiação UV. A) sem exposição, B) após 5 min., C) após 10 min., D) após 15 min., E) após 20 min., F) após 30 $\min$.

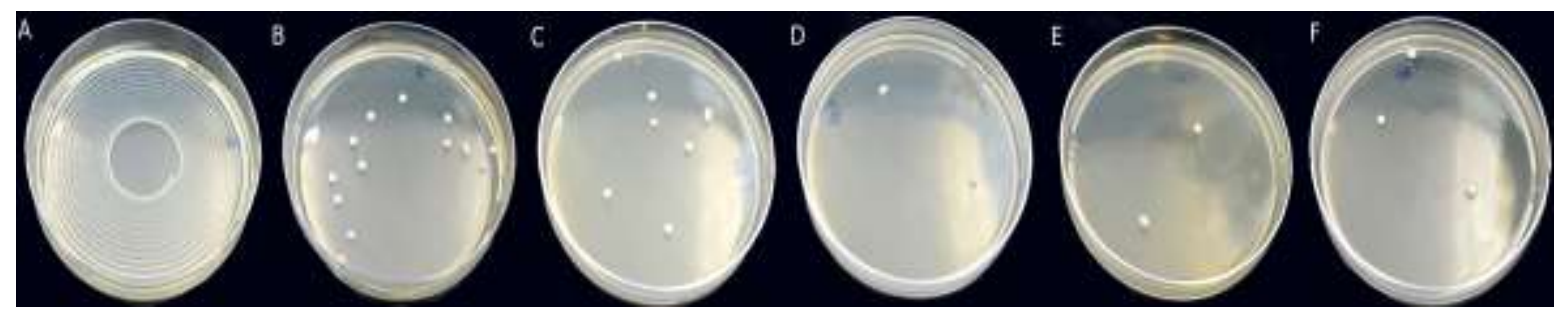

Fonte: Autores (2021).

O tempo necessário para a desinfecção com a utilização do dispositivo desenvolvido neste estudo, a uma distância de 1 (um) metro e com incidência perpendicular dos raios foi inferior a 20 min. para todos os micro-organismos testados (Fig. 8 ). Resultados semelhantes foram obtidos por Szeto et al. (2020). Buonanno et al. (2020) avaliaram a eficiência da irradiação de UVC com comprimento de onda entre 207-222 nm sobre coronavirus humanos, e constataram que este método foi eficiente em eliminar as partículas virais, e observaram que que devido a grande similaridade entre as diferentes espécies de coronavirus, esta metodologia pode potencialmente eliminar o vírus SARS-COV-2 causador da COVID-19 presente no meio ambiente.

Figura 8. Tempo de exposição à radiação UV-C e padrão de morte celular de Candida albicans, Staphylococcus aureus e Escherichia coli.
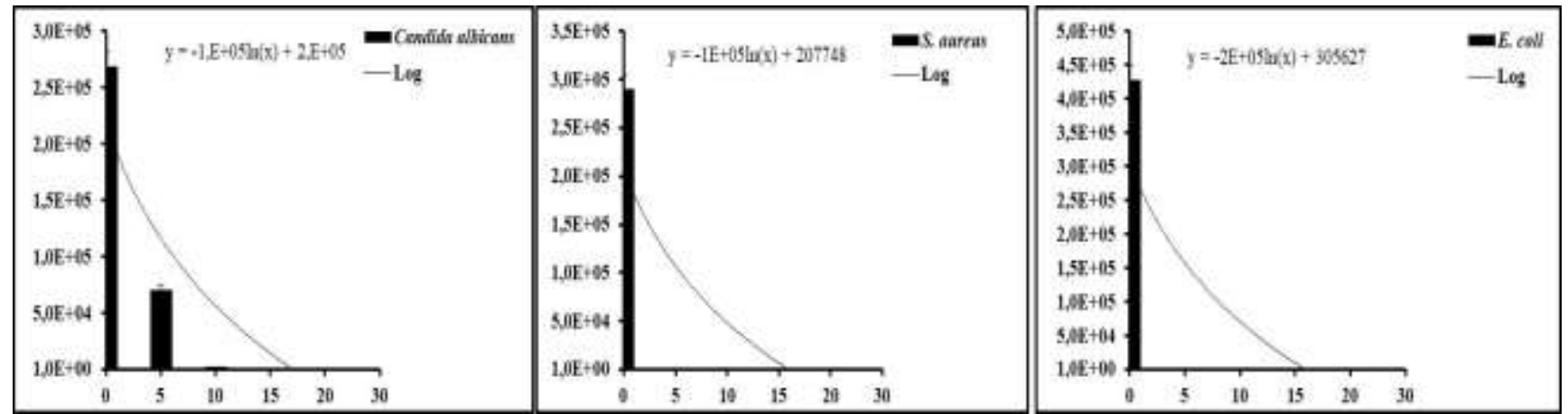

Fonte: Autores (2021).

Diversos micro-organismos como bactérias, fungos e vírus são capazes de se disseminar por rotas ambientais, incluindo o ar e superfícies inertes ou indiretamente após o toque em uma superfície contaminada (Raeiszadeh \& Adeli, 2020).

Até o momento é sabido que a disseminação da Covid-19 é transmitida diretamente pelo vírus de pessoa a pessoa, dentre outras rotas de transmissão. E a melhor maneira de lidar com a pandemia instalada é primeiramente, reduzir o risco de infecção pelo vírus, bloqueando essas rotas. Para tanto, a organização mundial da saúde recomenda o uso de máscaras faciais, lavagem das mãos frequentemente ou qualquer barreira, que reduza a propagação do vírus (Ferreira, et al., 2020; Raeiszadeh \& Adeli, 2020).

No entanto, a eficácia dessas ações preventivas é limitada, particularmente em ambientes internos onde o ar circulante pode se tornar contaminado ou superfícies frequentemente tocadas podem mediar a transmissão (Garcia de Abajo, et al., 2020; Raeiszadeh \& Adeli, 2020). 
De acordo com Van Doremalen et al. (2020), o vírus SARS-CoV-2 pode manter se viável em superfícies por várias horas, dependendo do material contaminado. Estes pesquisadores detectaram a permanência em superfícies de materiais como cobre, papelão, aço inoxidável e plástico mantidos entre 21 e $23{ }^{\circ} \mathrm{C}$ e $40 \%$ de umidade relativa em até 7 dias. Evidenciando que o contato direto com superfícies contaminadas, é um potencial mecanismo de transmissão viral.

Desta forma, para minimizar o risco de infecções virais e por outros patógenos, diversas técnicas de controle podem ser aplicadas, como: esterilização por calor, desinfetantes químicos, filtração e irradiação ultravioleta (UV). Todavia, não existe um método de desinfecção que seja o ideal para todas as situações ou superfícies. Assim, se faz necessário explorar diferentes métodos de controle para reduzir a transmissão aérea e por fômites (Raeiszadeh \& Adeli, 2020).

Dentre essas tecnologias a exposição à luz ultravioleta (UV-C) tem se mostrado eficiente contra diferentes vírus, bactérias e fungos (Haji Malayeri, et al., 2016; Buonanno, et al., 2020). Este método não utiliza produtos químicos, é altamente eficiente no controle de micro-organismos (Raeiszadeh \& Adeli, 2020).

Este trabalho desenvolveu um dispositivo para desinfecção a base de radiação UV-C portátil, de baixo custo que demonstrou eficácia e qualidade para o processo de desinfecção de forma segura em superfícies e que poderá ser utilizado no controle do vírus SARS-Cov-2, visto que relatos mais recentes da literatura demostram que a aplicação de lâmpadas UV tiveram um papel importante para a contenção da pandemia COVID-19, assim como o controle de outros patógenos (Raeiszadeh \& Adeli, 2020; Buonanno, et al., 2020).

\section{Considerações Finais}

O dispositivo desenvolvido neste estudo pode ser construído por boa parte das empresas e população com baixo investimento financeiro. O dispositivo foi eficaz para reduzir o risco de contágio de diferentes micro-organismos patogênicos em menos de 20 minutos, sugerindo sua efetividade contra SARS- COV-2 causador da pandemia COVID-19. Contudo é necessário observar-se as medidas de segurança para a utilização de luz UV-C, o contato com pele e olhos devem ser evitados fortemente.

\section{Agradecimentos}

Os autores agradecem ao Ministério da Educação pelo apoio financeiro para execução da pesquisa, à Universidade Federal do Tocantins por meio da PROPESQ pela disponibilização da infraestrutura de pesquisa. Ao Conselho nacional de desenvolvimento científico e tecnológico (CNPQ) pela concessão de bolsa de produtividade em desenvolvimento tecnológico e extensão inovadora (DTI).

\section{Referências}

Buonanno, M., Welch, D., Shuryak, I., \& Brenner, D. J. (2020). Far-UVC light efficiently and safely inactivates airborne human coronaviruses. Nature Researcharticle, 10:10285.

Cadnum, J. L., Li1, D. F., Jones, L. D., Redmonde, S. N., Pearlmutter, B., Wilson, B. M., \& Donskey, C. L. (2021). Evaluation of Ultraviolet-C Light for Rapid Decontamination of Airport Security Bins in the Era of SARS-CoV-2. Pathogens and Immunity, 5 (1), $133-142$.

Choi, H., Chatterjee, P., Lichtfouse, E., Martel, J. A., Hwang, M., Jinadatha, C., \& Virender K. S. (2021). Classical and alternative disinfection strategies to control the COVID-19 virus in healthcare facilities: a review. Environmental Chemistry Letters.

Dos Santos, V. C., Da Fonseca, R. C. C., \& Cardoso, D. D’O. (2008). Fator de visão da radiação: aplicação na determinação da irradiância de lâmpada ultravioleta de bronzeamento artificial. RMCT $3{ }^{\circ}$ QUADRIMESTRE DE 2008 (rmct.ime.eb.br).

Dhama, K., Khan, S., Tiwari, R., Sircar, S., Bhat,S., Malik, Y. S., Pal Singh, K., Chaicumpa, W., Bonilla-Aldana, D. K., \& Rodriguez-Morales, A. J. (2020). Clinical Microbiology Reviews, 33 (4).

Ferreira, E. M. S., de Souza, B. G., Silva, P. W. P., Miranda, W. L., Pimenta, R. S., \& Silva, J. F. M. (2020). Sars-cov-2 - aspectos relacionados a biologia, propagação e transmissão da doença emergente covid-19. Desafios - Revista Interdisciplinar Da Universidade Federal Do Tocantins, 7 (Especial-3), 9-17. 
Research, Society and Development, v. 10, n. 6, e31310615817, 2021

(CC BY 4.0) | ISSN 2525-3409 | DOI: http://dx.doi.org/10.33448/rsd-v10i6.15817

García de Abajo, F. J., Hernández, R. J., Kaminer, I., Meyerhans, A., Rosell-Llompart, J., \& Sanchez-Elsner, T. (2020). Back to Normal: An Old Physics Route to Reduce SARS-CoV-2 Transmission in Indoor Spaces. ACS Nano, 14, 7704.

Haji Malayeri, A., Mohseni, M., Cairns, B., \& Bolton, J. R. (2016). Fluence (UV Dose) Required to Achieving Incremental Log Inactivation of Bacteria, Protozoa, Viruses and Algae. IUVA News, 18, 4-6.

Howell, J. R. (2021). A Catalog Of Radiation Heat Transfer Configuration Factors. University of Texas at Austin. $<$ http://www.thermalradiation.net/tablecon.html>.

Kampf, G., Todt, D., Pfaender, S., \& Steinmann, E. (2020). "Persistence of coronaviruses on inanimate surfaces and their inactivation with biocidal agents". Journal of Hospital Infection, 104 (3).

Kowalski, W. J. (2001). Design and optimization of UVGI air desinfection systems. Doctoral thesis, The Pennsylvania State University.

Kowalski, W. J. (2009). Ultraviolet Germicidal Irradiation Handbook: UVGI for Air and Surface Disinfection. 504p.

Modest, M. F. (2013). Radiative Heat Transfer., McGraw-Hill, (Third Edition).

Morais, V. N, Dias, F. C. B, Santana, T. B. A, Maciel, L. G., Souza, Y. C de S., Mescoloti1, A. A., Milagres, F. A. de P., \& Pimenta, R. S. (2021). Doença pelo coronavírus 2019: Uma revisão sistemática. Desafios - Revista Interdisciplinar Da Universidade Federal Do Tocantins, 8 (1), 1-17.

Raeiszadeh, M., \& Adeli, B. (2020). A Critical Review on Ultraviolet Disinfection Systems against COVID-19 Outbreak: Applicability, Validation, and Safety Considerations. ACS Photonics, 11, 2941-295.

Silva, J. M. B., Loureiro, L. H., Silva, I. C. M., \& Novaes, M. L. (2021). Coronavirus and the disinfection and reprocessing protocols of hospital articles. Research, Society and Development, 9 (9) e29996187.

Torres, A. E., Lyons, A. B., Narla, S., Kohli, I., Parks-Miller, A., Ozog, D., Hamzavia, I. H., Henry W., \& Lim, H. W. (2020). Ultraviolet-C and other methods of decontamination of filtering facepiece N-95 respirators during the COVID-19 pandemic. Photochem. Photobiol. Sci., 19, 746.

Three-Dimensional View Factors, 2021. Disponível em: 〈http://fchart.com/ees/heat_transfer_library/shape_factors/shape_factors.html>. Acesso em: 08 de abril de 2021

Van Doremalen, N., Bushmaker, T., Morris, D. H., Holbrook, M. G., Gamble, A., Williamson, B. N., Tamin, A., Harcourt, J. L., Thornburg N. J., Gerber, S. I., Lloyd-Smith, J. O., \& de Wit, E. (2020). Aerosol and Surface Stability of SARS-CoV-2 as Compared with SARS-CoV-1. N. Engl. J. Med., 382 (16), 1564.

Szeto, W., Yam, W. C., Huang, H., \& Leung, D. Y. C (2020). The efficacy of vacuum-ultraviolet light disinfection of some common environmental pathogens. BMC Infectious Diseases, 20 (127).

Zhou, E., Yu, T., Du, R., Fan, G., Liu, Y., Liu, Z., Xiang, J., Wang, J., Song, B., Gu, X., Guan, L., Wei, Y., Li, H., Wu, X., Xu, J., Tu, S., Zhang, Y., Chen, H., \& Cao, B. (2020). "Clinical course and risk factors for mortality of adult inpatients with COVID-19 in Wuhan, China: a retrospective cohort study". The Lancet, 395, 10229-62. 